\title{
From robotics technology to environmental crimes involving robots
}

\author{
Ildar Begishev ${ }^{1}$, Zarina Khisamova ${ }^{2, *}$, and Vitaly Vasyukov ${ }^{3}$ \\ ${ }^{1}$ Kazan Innovative University named after V.G. Timiryasov, Moskovskaya str., 42, Kazan, Russia \\ ${ }^{2}$ Krasnodar University of the Ministry of Internal Affairs of the Russian Federation, Yaroslavskaya \\ str., 128, Krasnodar, Russia \\ ${ }^{3}$ Moscow state Institute of international relations (University), Orel legal Institute of the Ministry of \\ Internal Affairs of Russia named after V. V. Lukyanov, Vernadsky Av., 76, Moscow, Russia
}

\begin{abstract}
The development of digital technologies gradually brings various changes to the life of mankind, related to the improvement of various sectors of the economy and industry. Gradually, the products of the development of these technologies become the tools without which it is impossible to imagine modern life. Relying entirely on technology in various aspects of their activities, human gradually becomes dependent on it. Highly dynamic rates of development of robotics and artificial intelligence lead to the fact that robots gradually take a place alongside humans. The capacity of some robots to self-study is a factor that cannot be ignored in modern legal relations, since the question of legal personality and responsibility for their actions was already involved. Researchers ask the question: how dangerous robotic actions can be against humans, and what legal means can prevent robots from committing crimes against their creator in particular, and the rule of law in general.
\end{abstract}

\section{Introduction}

The current century is characterized by the rapid development of modern technologies that use artificial intelligence. A special role is played by the use of AI in robotics. AI-based robots based are widely used in industry, in the military field, in space exploration, in oceanology and other areas of human activity [1].

Historically, the concepts of robot and artificial intelligence were inextricably linked to each other. As ideas about the subject of research in both these areas developed, robotics and AI gradually separated, leaving, however, a vague confidence in the need for their final integration.

It is no coincidence that one of the directions of $\mathrm{AI}$ is still considered purposeful behavior of robots (the creation of intelligent robots that can autonomously perform operations to achieve goals set by humans) [2]. Since the technological advantage of AI has huge economic and political benefits, the rapid technological growth of AI can be called inevitable. One of the most important issues for modern society today is the issue of responsibility for causing harm by robots. In particular, autonomous vehicles that are already appearing on the roads of

${ }^{*}$ Corresponding author: zarahisamova@gmail.com 
cities and towns. Most car companies are planning to launch fully automated vehicles in the near future, which will change the aspect of liability for damage caused by autonomous vehicles. The researchers conclude that the responsibility of autonomous vehicles will depend on the specific details of the situation, the role of the driver, the level of autonomy exercised by the vehicle, environmental factors, etc. The researchers argue that the current laws and regulations will not apply after the mass release of autonomous vehicles on the roads. Existing laws need to be amended and new laws adopted to provide a regulatory framework that is appropriate for automated driving. Developed countries such as the United States, the United Kingdom, and Germany are already moving in this direction, setting up working groups to review existing laws and develop new ones. policy makers are working with other stakeholders to ensure a fair legal system before autonomous vehicles are used on a wider scale [2]. The legal regulation of the development and implementation of robotics today is based on two principles: An effective regulatory framework will require the establishment of various defined legal standards for AI at the level of its attributes, the establishment of responsibility in connection with it, and the monitoring of compliance with the standards [3-4].

\section{Methods}

The methodological basis of the research is a systematic approach to the study of the ethical, legal and technological foundations of the application and development of robotics. During the research, the main problematic aspects related to the development of robotic systems were classified and analyzed and their use for criminal purposes. When processing the actual material, such traditional scientific methods as dialectical, logical, the method of scientific generalizations, content analysis, comparative analysis, synthesis, source studies, etc. were used. Their application made it possible to ensure the validity of the analysis, theoretical and practical conclusions and developed proposals. The use of a broad methodological base ensured the representativeness of the conclusions made by the authors.

\section{Results}

Regulation of the responsibility of robots for crime is particularly problematic. Gabriel Hallevy, a well-known Israeli criminal law expert, notes that people deal with any violations of law and order with the help of criminal law, through the criminal justice system. Accordingly, human societies define criminal offences and use social mechanisms for their application [5].

This path was originally developed by people and for people. However, with the development of technology, not only people commit criminal crimes. Accordingly, in the twenty-first century, criminal legislation should provide for adequate penalties for crimes committed with artificial intelligence.

As a result, when robots and humans are directly or indirectly involved in the commission of a particular crime, responsibility for the commission of crimes must be unavoidable. This is one of the measures of social control that will protect society from the consequences of crimes committed with the participation of robots and AI [5].

It should be noted that the study of the legal aspects related to the socially dangerous consequences of the use of AI constitutes an independent layer of serious and sufficiently thorough criminal law research, which should result in a conceptually new legal model for the regulation of relations in this field [6].

Suzanne Beck also notes the importance of the necessary regulation of legal liability due to the dynamic development of robotics. She points out that the development of robotics 
poses problems in terms of assigning responsibility among individuals. This may leave the person whose rights have been violated by the robot without the possibility of satisfactions for damages or, in general, making someone legally responsible for the damage caused. The author suggests several possible solutions to these problems that arise in connection with technological developments, for example, the introduction of the so-called "electronic face". However, the researcher points out that such decision will have consequences for social categories such as "personality", "dignity" or "responsibility" [7].

Among the reasons behind the necessary legal regulation of responsibility for crimes involving robots, Suzanne Beck cites the increasing autonomy of the latter. According to the author, they are increasingly close to human thinking patterns [7].

To overcome legal problems, it is necessary to develop rules of human behavior, including the programming and use of these machines, as well as to adapt existing legal norms to the emerging legal relations involving AI and robots. The researcher also considers some problems associated with the use of robotics products, which society may face in the very near future, and some of these problems already occur. These are robots that cause damage in production, robots that commit illegal actions due to programmer errors, robots that are purposefully programmed by humans to commit offenses and crimes [7].

The development of robotics really creates problems with assigning responsibility not only in the case of damage caused by robots to third parties. This also means that people who create autonomous cars need to remember their responsibility to society. The author comes to the conclusion that the discussion of responsibility and potential legal status in the context of robotics means something more than raising the question "Who is responsible if something goes wrong?", Accordingly, a legal category of "electronic person" could be introduced only if there was a clear answer to the question of what impact it would have on society. It is necessary to understand what will happen if a person intentionally transfers decision-making to machines [7].

The category of guilt in criminal law related to the development of robotics and AI was the subject of consideration by R. I. Dremlyuga and N. G. Prisekina. They consider AI systems and robots as instruments of crime from the point of view of the norms and principles of criminal law. And discuss how the legal framework in the field of determining guilt can be applied to offenses committed using AI [8].

The authors analyze the current state of regulation of the category of "guilt" in the field of criminal law, which occurs both in intentional and negligent crimes, and also compare these two forms of guilt.

The analysis in the article shows that law enforcement officers and legislators should reconsider the approach to determining guilt in the case of the use of artificial intelligence systems to commit intentional crimes. Because artificial intelligence system in some sense has its own developed knowledge and will, the courts cannot rely on the traditional concept of guilt in intentional crimes, where intent is clearly defined in accordance with the actions of the criminal [8].

Criminal negligence is considered by the authors from the point of view of criminal liability of the developer. He acts as a person who can influence and anticipate the damage caused by the artificial intelligence system he created. If product developers would be free from any form of criminal liability for harm caused by their products, this will lead to extremely negative social consequences. The situation when a person developing an artificial intelligence system must take into account all the potential harm caused by the product also has negative social consequences. Researchers urge to find a balance between these two extreme positions. The authors suggest to revise the generally accepted concept of guilt in criminal law. They believe that new criteria can be developed to assess the degree of human guilt in the case of using a robot as a weapon of crime. This new paradigm of guilt cannot be universal, as an innovative legal concept must be consistent with national legal tradition [8]. 
In addition, new rules for assessing guilt should be developed taking into account the features of artificial intelligence technologies. For example, the legal concept should take into account the fact that robots and $\mathrm{AI}$ in some sense have their own knowledge and will [8].

\section{Discussion}

\subsection{Robotics technologies}

It has become common practice to determine the requirements for intelligent robots based on the tasks facing the device. For example, factors such as the need for periodic recharging of the device and additional information collection to determine the parameters of the world model in conditions of incomplete information require the introduction of the concepts of needs (energy and information). The satisfaction of the latter should imply the presence of purposefulness, dynamic planning, etc.

Further development of intelligent robots is the introduction of a hierarchy of management levels - strategic, tactical and adaptive [3].

It is generally believed that an intelligent robot has a so-called model of the external world or internal environment, which allows the robot to act in conditions of information uncertainty. If this model is implemented in the form of a knowledge base, then it is advisable that this knowledge base be dynamic. At the same time, the correction of inference rules in a changing environment naturally implements the mechanisms of self-learning and adaptation.

Intelligent control is the next highest type of control after adaptive control, and it is in its infancy. In nowadays adaptive systems have been created with some elements of artificial intelligence in the form of the ability to perceive and analyze a rather complex and changing external environment and make adequate decisions on behavior. For a qualitative leap in the direction of creating full-fledged intelligent systems, new hardware is required on a fundamentally new element base.

The increase in the level of artificial intelligence is primarily due to the development of the hierarchical structure of environment models by forming more and more generalized, more abstract levels of its representation. One of the most generalized types of environment models is logical-linguistic models. They are used for the most complex objects with mixed reactions to the same situations, which cannot be described formally mathematically and therefore are described heuristically based on expert assessments in a language close to natural. Examples of such control object are the first and foremost a system that includes people. Artificial intelligence methods can be used in control systems not only in the systemwide control loop, i.e. for the formation of control, but also for solving various local problems of individual robotic systems. In this case, the process of controlling the robot does not become intelligent, just as in adaptive control systems, the presence of internal adaptation in certain parts of the system does not make the control as a whole adaptive [4].

The relevance of creating artificial intelligence at the present time is associated with the complexity of the problems that modern humanity has to solve. Such problems include space exploration, forecasting of natural disasters and anthropogenic impact on the environment, the creation of complex engineering projects, the use of modern technology in medicine and many scientific studies. In addition, artificial intelligence will help a human cope with tasks that he cannot do (complex calculations and analysis) and simply expand the intelligence given to him by nature. Modern artificial intelligence systems are able to master many more specialties and effectively control robotic devices than the operator, thanks to a much larger number of various information sensors and devices. 


\subsection{Crimes involving robots}

Geraint Howells, Christian Twigg-Flesner and Chris Willett turn their attention to the study of the following question: should intangible products, such as applications and other software not delivered on a tangible medium, qualify as products under the EU Product Liability Directive. It addresses the relevant questions raised by the European Commission, which recently announced an assessment of the directive with a view to adapting it to the digital age. Researchers draw a line between information (in material or non-material form) that should not lead to liability, and material or non-material information that can cause harm to society. The latter should be considered as an object falling under the scope of the Directive on liability for products of inadequate quality [9].

The authors consider that in the context of sales, a separate category of compliance is being created, including rules for the sale and distribution of digital products of goods. This is particularly necessary in view of the need to adapt remedies to the digital context. With regard to product liability, a distinction should be made between intellectual property, which is information and should be covered by negligence law, and software that can cause material damage and should be subject to the EU Directive [9].

S. Bortnikov examines the relationship of responsibility arising from the production, acquisition and use of robots and software. The author believes that for the development of the robot market, it is necessary to create minimally comfortable conditions from the economic, legal and administrative points of view. This is, first of all, the creation of an open environment for innovation, which requires legal transparency. The researcher considers the need to adjust the legal regulation, especially in the field of civil and business legislation, in order to create a condition for the legal turnover of robots and AI [10].

The author discusses the issue of human and machine communication tools, including the impact on the legal principles of regulating liability relations. The identification of responsible persons implies the possibility of conferring on the robot a special legal personality, such as the status of an electronic person. The researcher also considers various mechanisms for ensuring and protecting the interests of consumers and users of electronic devices. In addition, the idea of mandatory liability insurance of robots, as it has already been implemented for vehicles, creation of special funds, establishment of a limit of liability, etc. is suggested [10].

Hutan Ashrafyan, considering the legal problems of the modern stage of robotics development, notes that the overwhelming predominance of works in this field are focused on the interaction of man and robot without fully taking into account the ethical leaving problem. The author proposes a new law on robotics, which is called AI on AI or artificial intelligence-on-artificial intelligence. This legislative act, according to the author, will prevent the abuse of intelligent beings created by man. The researcher not only offers guidance for the future of robotics and artificial intelligence but also offers a deep and useful reflection on the just principles of human society [11].

The team of Russian researchers also considers the problems of legal regulation of robotics and artificial intelligence in society from a psychological point of view. The authors emphasize the lack of readiness of modern legal science and practice for conceptual and legal design, normative and technical development of normative legal acts aimed at legislative consolidation and regulation of the processes of using artificial intelligence and robots in public relations, as well as the definition of responsibility and appropriate consumer protection regimes [12].

The authors identify and analyze two consecutive stages: 1) development and introduction of necessary changes to existing branches of Russian law; 2) conceptual-legal and doctrinal-legal formulation of key development priorities, as well as the creation of a 
new integrated branch of law-robotic law, which has an independent subject and method of legal regulation [12].

The process of establishing the legal framework for regulating these processes should be developed in two consecutive stages. The first stage involves the development and introduction of necessary changes to existing branches of Russian law. At the same time, the main efforts of the scientific community, experts and legislators should be focused on creating legal regimes for regulating unmanned aerial vehicles or unmanned aerial vehicles that are widely used in various spheres of life [12].

In turn, the second stage should be conceptual and doctrinal, that is aimed at the theoretical understanding of domestic and foreign experience. This will allow the formulation of key development priorities, as well as the creation of a new integrated branch of law robotic law, which has an independent subject and method of legal regulation [12].

Kate J. Hayward and Mattis Maas examine the problem of crime, which is associated with the emergence of robots and artificial intelligence, and assess its danger to society [13]. Gradually considering the negative consequences of this phenomenon for society, the authors consider it necessary to legally consolidate the legal responsibility of robots and AI for committing criminal crimes.

Rolf H. Weber and Dominic N. Steiger focus their research on the problem of defining models of robot and AI responsibility in the digital age. The authors note that new "actors" such as robots complement a complex mix of technologies that challenge existing concepts of contract and tort law. In addition, technology creates new areas of responsibility within companies and in their interactions with customers and other stakeholders. These risks are even greater as the number of obligations related to compliance with data protection and consumer protection legislation increases. To cope with the additional responsibility, enterprises must understand the nature of risks and take appropriate measures to minimize their impact [14].

The concept of "robots as animals" is considered in the works of Richard Kelly, Enrique Scherer, Mikael Gomez and Monica Nicolescu. In this concept, robots are compared to domesticated animals for legal purposes in liability disputes. Researchers review the laws concerning domesticated animals in Europe, Asia and North America, summarize the laws of several countries concerning dangerous pets, in particular dogs, and show how these laws can be adapted for use in regulating relationships involving robots and AI [15].

Andreas Mathias explores the problem of assigning responsibility for the actions of AI and robots to humans. The author concludes that if we want to avoid the injustice of placing responsibility on people for the actions of machines over which they cannot have sufficient control, we must find a way to close the gap of responsibility in moral practice and legislation. The growing use of autonomous learning and operating machines in all areas of modern life will no longer allow us to ignore this gap [16].

Jan Broersen notes that as intelligent systems are increasingly integrated into our daily lives, the division of responsibility between humans and artificial agents is becoming increasingly important [17].

The problem of outsourcing responsibility to intelligent systems is quite relevant in the modern period. If we want to protect society from the risks of outsourcing responsibility to intelligent autonomous devices, we must find ways to regain control of AI systems. This is possible by using an approach based on the representation of the responsibility and risks of relationships that occur with the participation of robots and AI [18]. A similar line of work is presented in the work of Ana Oliveira [19].

Matyazh Pepper, Mahmut Lakes and Yan Chojnik explore the socio-legal problems of artificial intelligence. They note that AI has a significant impact on many aspects of society and industry, ranging from scientific discoveries, health care and medical diagnostics to smart cities, transport and sustainable development. Within the framework of the reality unfolding 
in the XXI century, a number of social and legal problems arise, for which people are poorly prepared [20].

Researchers analyze social dilemmas where individual interests diverge from the interests of others, and where artificial intelligence can be particularly difficult to make the right decision. An example of this is the well-known social dilemma of autonomous vehicles. The authors set themselves the task of determining who is legally responsible and to what extent [21].

Joanna George. Bryson, Michailis E. Diamantis, and Thomas D. Grant set out to address the legal gap in the field of legal relations related to robotics. The authors believe that giving robots legal personality is morally unnecessary and legally problematic. Almost inevitably, there will be asymmetries in specific legal systems, situations similar to the situation of an investor under investment contracts, who can hold the defendant liable, but under the same contracts is not himself liable [22].

Hutan Ashrafyan addresses the issues of moral responsibility of AI and robots for their own actions. On a practical level, the achievement of responsibility by artificial intelligence and robots can benefit from the established responsibilities and responsibilities of human society, as their existence exists in this field. These general rules can be further interpreted through legal principles, many of which are preserved in ancient roman law. The ultimate and unified goal of establishing these responsibilities is to advance humanity and permanently preserve the basic principles of humanity current developments and innovations in artificial intelligence and robotics offer the promised possibilities of computer consciousness, sensitivity and rationality [23].

One of the most important issues for modern society today is the responsibility of autonomous vehicles, which are already appearing on the roads of cities and settlements. Most car companies plan to launch fully automated vehicles in the near future, which will change the aspect of liability for damage caused by autonomous vehicles. The researchers conclude that the responsibility of autonomous vehicles will depend on the specific details of the situation, the role of the driver, the level of autonomy exercised by the vehicle, and environmental factors, etc. The researchers argue that the current laws and regulations will not apply after the mass release of autonomous vehicles on the roads. It is necessary to amend existing laws and adopt new laws to provide a regulatory framework that is appropriate for automated driving. Developed countries such as the US, UK and Germany are already moving in this direction, setting up working groups to review existing laws and develop new ones. politicians work with other stakeholders to ensure a fair legal system before autonomous vehicles are used on a larger scale [24].

\section{Conclusion}

The processes of using robotics for criminal purposes have an increased public danger and undoubtedly should be regulated by criminal law means. The study of the legal aspects related to the socially dangerous consequences of the use of AI constitutes an independent layer of serious and sufficiently thorough criminal law research, which should result in a conceptually new legal model for the regulation of relations in this field [6]. The legal regulation in this field is necessary for the development of standards, without which it will be impossible to effectively develop robotics and artificial intelligence in Russia.

\section{References}

1. I.R. Begishev, Z.I. Khisamova, S.G. Nikitin, The Organization of Hacking Community: Criminological and Criminal Law Aspects, Rus. J. of Crim. 14(1), 96-105 (2020) 
2. Z.I. Khisamova, I.R. Begishev, E.L. Sidorenko, Artificial Intelligence and Problems of Ensuring Cyber Security, Intern. J. of Cyber Crimin. 13(2), 564-577 (2019)

3. A.Yu. Bokovnya, I.R. Begishev, Z.I. Khisamova, et.al., Pressing Issues of Unlawful Application of Artificial Intelligence, International Journal of Criminology and Sociology 9, 1054-1057 (2020)

4. I.R. Begishev, Z.I. Khisamova, Criminological Risks of Using Artificial Intelligence, Russian Journal of Criminology 12(6), 767-775 (2018)

5. G. Hallevy, The Basic Models of Criminal Liability of AI Systems and Outer Circles (2019)

6. Z.I. Khisamova, I.R. Begishev, Criminal Liability and Artificial Intelligence: Theoretical and Applied Aspects, Rus. J. of Crimin. 13(4), 564-574 (2019)

7. S. Beck, Legal Responsibility in the Case of Robotics, Developing Support Technologies. Biosystems \& Biorobotics 23 (2018)

8. R. Dremliuga, N. Prisekina, The Concept of Culpability in Criminal Law and AI Systems, Journal of Politics and Law 13(3), 256-262 (2020)

9. G. Howells, C. Twigg-Flesner, C. Willett, Product Liability and Digital Products. In: Synodinou TE., Jougleux P., Markou C., Prastitou T. (eds) EU Internet Law. Springer, Cham (2017)

10. S.P. Bortnikov, Robots Liability or Liability for Products? In: Ashmarina S., Mesquita A., Vochozka M. (eds) Digital Transformation of the Economy: Challenges, Trends and New Opportunities, Advances in Intelligent Systems and Computing 908 (2020)

11. H. Ashrafian, AIonAI: a humanitarian law of artificial intelligence and robotics, Science and Engineering Ethics 21(1), 29-40 (2014)

12. P. Baranov, A. Mamychev, A. Plotnikov, D. Voronov, E. Voronova, Problems of Legal Regulation of Robotics and Artificial Intelligence from the Psychological Perspective, Propósitos y Representaciones 8(2), e511 (2020)

13. K.J. Hayward, M.M. Maas, Artificial intelligence and crime: A primer for criminologists, Crime, Media, Culture: An International Journal 1-25 (2020)

14. R.H. Weber, D.N. Staiger, New Liability Patterns in the Digital Era. In: Synodinou TE., Jougleux P., Markou C., Prastitou T. (eds) EU Internet Law. Springer, Cham (2017)

15. R. Kelley, E. Schaerer, M. Gomez, M. Nicolescu, Liability in Robotics: An International Perspective on Robots as Animals, Advanced Robotics 24(13), 1861-1871 (2010)

16. A. Matthias, The responsibility gap: Ascribing responsibility for the actions of learning automata, Ethics and Information Technology 6, 175-183 (2004)

17. J. Broersen, Responsible Intelligent Systems, Künstl Intell 28, 209-214 (2014)

18. A. Oliveira, Subject (in) Trouble: Humans, Robots, and Legal Imagination. Laws 9(2), 10 (2020)

19. M. Perc, M. Ozer, J. Hojnik, Social and juristic challenges of artificial intelligence, Palgrave Communications 5(61), 1-7 (2019)

20. J.J. Bryson, M.E. Diamantis, T.D. Grant, Of, for, and by the people: the legal lacuna of synthetic persons, Artificial Intelligence and Law 25, 273-291 (2017)

21. H. Ashrafian, Artificial Intelligence and Robot Responsibilities: Innovating Beyond Rights, Science and Engineering Ethics 21, 317-326 (2015)

22. M. Alawadhi, J. Almazrouie, M. Kamil, et al., Review and analysis of the importance of autonomous vehicles liability: a systematic literature review, Int. J. Syst. Assur. Eng. Manag. 11, 1227-1249 (2020) 
23. A. Chandra, Liability Issues in Relation to Autonomous AI Systems (2017)

24. I.I. Bikeev, P.A. Kabanov, I.R. Begishev, Z.I. Khisamova, Criminological Risks and Legal Aspects of Artificial Intelligence Implementation, In Proceedings of the International Conference on Artificial Intelligence, Information Processing and Cloud Computing, New York: ACM (2019) 